\title{
Evidence-based guideline: Treatment of painful diabetic neuropathy
}

Report of the American Academy of Neurology, the American Association of Neuromuscular and Electrodiagnostic Medicine, and the American Academy of Physical Medicine and Rehabilitation

an $\mathbb{B}$ ]

\section{ABSTRACT}

Objective: To develop a scientifically sound and clinically relevant evidence-based guideline for the treatment of painful diabetic neuropathy (PDN).

Methods: We performed a systematic review of the literature from 1960 to August 2008 and classified the studies according to the American Academy of Neurology classification of evidence scheme for a therapeutic article, and recommendations were linked to the strength of the evidence. The basic question asked was: "What is the efficacy of a given treatment (pharmacologic: anticonvulsants, antidepressants, opioids, others; and nonpharmacologic: electrical stimulation, magnetic field treatment, low-intensity laser treatment, Reiki massage, others) to reduce pain and improve physical function and quality of life (QOL) in patients with PDN?"

Results and Recommendations: Pregabalin is established as effective and should be offered for relief of PDN (Level A). Venlafaxine, duloxetine, amitriptyline, gabapentin, valproate, opioids (morphine sulfate, tramadol, and oxycodone controlled-release), and capsaicin are probably effective and should be considered for treatment of PDN (Level B). Other treatments have less robust evidence or the evidence is negative. Effective treatments for PDN are available, but many have side effects that limit their usefulness, and few studies have sufficient information on treatment effects on function and QOL. Neurology $2011 ; 76: 1758-1765$

Adress correspondence and reprint requests to American Academy of Neurology, 1080 Montreal Avenue, St. Paul, MN 55116

guidelines@aan.com

\section{GLOSSARY}

AAN = American Academy of Neurology; NNT = number needed to treat; PDN = painful diabetic neuropathy; QOL = quality of life; $\mathbf{R C T}=$ randomized controlled trial; SF-MPQ $=$ Short Form-McGill Pain Questionnaire; SF-QOL = Short Form-Quality of Life; VAS = visual analog pain scale.

Diabetic sensorimotor polyneuropathy represents a diffuse symmetric and length-dependent injury to peripheral nerves that has major implications on quality of life (QOL), morbidity, and costs from a public health perspective. ${ }^{1,2}$ Painful diabetic neuropathy (PDN) affects $16 \%$ of patients with diabetes, and it is frequently unreported (12.5\%) and more frequently untreated (39\%). ${ }^{3}$ PDN presents an ongoing management problem for patients, caregivers, and physicians. There are many treat- ment options available, and a rational approach to treating the patient with PDN requires an understanding of the evidence for each intervention.

This guideline addresses the efficacy of pharmacologic and nonpharmacologic treatments to reduce pain and improve physical function and QOL in patients with PDN. The pharmacologic agents reviewed include anticonvulsants, antidepressants, opioids, anti-arrhythmics, cannabinoids, aldose reductase inhibitors, protein kinase
Supplemental data at www.neurology.org
e-Pub ahead of print on April 11, 2011, at www.neurology.org.

From the University Health Network (V.B., B.P.), University of Toronto, Toronto, Canada; Department of Neurology (J.E.), LSU School of Medicine, New Orleans, LA; University of Washington (G.M.F.), Seattle; University of Wisconsin (M.B.), Madison; Dartmouth Hitchcock Medical Center (J.C.), Lebanon, NH; Department of PM\&R (D.D.), Medical College of Wisconsin, Milwaukee; University of Michigan (E.F.), Ann Arbor; Humboldt Neurological Medical Group, Inc. (D.J.I.), Eureka, CA; Department of Neurology (J.W.R.), University of Maryland School of Medicine, Baltimore; and University of Calgary (D.Z.), Calgary, Canada.

Appendices e-1-e-5 and References e1-e46 are available on the Neurology ${ }^{\circledR}$ Web site at www.neurology.org.

Approved by the AAN Quality Standards Subcommittee on November 13, 2010; by the AAN Practice Committee on December 15, 2010; by the AAN Board of Directors on February 10, 2011; by the Neuromuscular Guidelines Steering Committee on October 8, 2010; by the AANEM Practice Issues Review Panel on January 15, 2011; by the AANEM Board of Directors on February 15, 2011; by the AAPM\&R Quality Practice \& Policy Committee on February 6, 2011; and by the AAPM\&R Board of Governors on March 11, 2011.

Disclosure: Author disclosures are provided at the end of the article. 
C beta inhibitors, antioxidants ( $\alpha$-lipoic acid), transketolase activators (thiamines and allithiamines), topical medications (analgesic patches, anesthetic patches, capsaicin cream, clonidine), and others. The nonpharmacologic modalities include infrared therapy, shoe magnets, exercise, acupuncture, external stimulation (transcutaneous electrical nerve stimulation), spinal cord stimulation, biofeedback and behavioral therapy, surgical decompression, and intrathecal baclofen.

DESCRIPTION OF THE ANALYTIC PROCESS In January 2007, the American Academy of Neurology (AAN), the American Association of Neuromuscular and Electrodiagnostic Medicine, and the American Academy of Physical Medicine and Rehabilitation convened an expert panel from the United States and Canada, selected to represent a broad range of relevant expertise. In August 2008, a literature search of MEDLINE and EMBASE was performed in all languages using the $\mathrm{MeSH}$ term diabetic neuropathies and its text word synonyms and key words for the therapeutic interventions of interest (see appendix e-1 on the Neurology ${ }^{\circledR}$ Web site at www.neurology.org for a full list of search terms). The search identified 2,234 citations, the titles and abstracts of which were reviewed by at least 2 authors for relevance, resulting in 463 articles. All of these articles were reviewed in their entirety, and of these, the panel identified 79 relevant articles. Each of these articles was rated by at least 2 authors according to the AAN criteria for the classification of therapeutic articles (appendix e-2), and recommendations were linked to the strength of evidence (appendix e-3) and to effect size of the intervention. Disagreements regarding classification were arbitrated by a third reviewer.

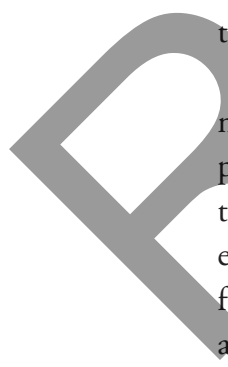

Articles were included if they dealt with the treatment of PDN, described the intervention clearly, reported the completion rate of the study, and defined the outcome measures clearly. The panel also considered the side effects of the treatment and measures of function and QOL, if any. Case reports and review articles were excluded.

We anticipated that studies would use varying measures for quantifying pain reduction. For the purposes of this guideline we preferred the following outcome measures, listed in order of preference:

1. The difference in the proportion of patients reporting a greater than $30 \%$ to $50 \%$ change from baseline on a Likert or visual analog pain scale (VAS) as compared to no treatment (placebo) or the comparative treatment. The Likert scale is an 11-point linear scale ranging from 0 (no pain) to
10 (maximum pain), and the patient rates his or her pain level on this scale. ${ }^{4-6}$

2. The percent change from baseline on a Likert or VAS as compared to no treatment (placebo) or the comparative treatment. ${ }^{6}$

3. Any other quantitative measure of pain reduction provided by the investigators.

For studies reporting the difference in the proportion of patients reporting a greater than $30 \%$ to $50 \%$ reduction in pain, we considered a risk difference of $>20 \%$ a large effect (number needed to treat [NNT] $<5$ ), a risk difference of $>10 \%$ to $20 \%$ (NNT $>5$ to 10) a moderate effect, and a risk difference of $\leq 10 \%$ (NNT $>10)$ a small effect, where risk difference is the reduction in pain in the active treatment group minus the reduction in the control group. For studies using a mean reduction from baseline on a Likert scale or VAS as compared to no treatment (placebo) or a comparative treatment, we considered a reduction difference of $>30 \%$ a large effect, $>15 \%$ to $30 \%$ a moderate effect, and $\leq 15 \%$ a small effect. For any other quantitative measure of pain reduction, we considered a reduction of $>30 \%$ a large effect, $>15 \%$ to $30 \%$ a moderate effect, and $\leq 15 \%$ a small effect.

The panel recognized that older studies generally lacked measures of QOL and function compared to more recent studies. Furthermore, the panel was aware that a standardized QOL measure for PDN or a standardized assessment of function is not available, and multiple instruments were used to measure QOL, such as the SF-36 ${ }^{\circledR}$ Health Survey, subsections of the SF-36, and function (such as sleep interference).

Studies with the highest levels of evidence for each intervention are discussed in the text, and data from other studies are shown in the tables. Details of Class I, II, and III studies are presented in the evidence tables.

ANALYSIS OF EVIDENCE In patients with PDN, what is the efficacy of pharmacologic agents to reduce pain and improve physical function and QOL? Anticonvulsants. We identified 20 articles relevant to anticonvulsants graded higher than Class IV (table e-1). Most of the randomized controlled trials (RCTs) rated as Class II instead of Class I had completion rates of less than $80 \%$ or the completion rate was not identified.

Four studies (3 Class I and 1 Class II) evaluated the efficacy of pregabalin. ${ }^{7-10}$ All studies found that pregabalin relieved pain, but the effect size was small relative to placebo, reducing pain by $11 \%-13 \%$ on the 11-point Likert scale in the Class I studies. A large dose-dependent effect $(24 \%-50 \%$ reduction in Likert pain scores compared to placebo) was ob- 
served in the Class II study. ${ }^{10}$ The NNT for a $50 \%$ reduction in pain was 4 at $600 \mathrm{~g} /$ day. $^{7-10}$ In the QOL measures, social functioning, mental health, bodily pain, and vitality improved, and sleep interference decreased, all changes with $p<0.05$.

Two studies (1 Class I and 1 Class II) evaluated the efficacy of gabapentin. ${ }^{11,12}$ In the Class I study, ${ }^{11}$ gabapentin had a small effect of net pain reduction from baseline of $11 \%$ on the 11 -point Likert scale compared to the change in placebo-treated patients, while a Class II gabapentin study showed no effect. ${ }^{12}$ Gabapentin had no effect on overall QOL in the single study reporting this measure, but did show an improvement in subsets of mental health and vitality. ${ }^{11}$

Two Class I trials evaluated the efficacy of lamotrigine. ${ }^{13,14}$ There was no difference in the primary outcome measures in the lamotrigine and placebo groups.

Two studies (both Class II) evaluated the efficacy of sodium valproate. ${ }^{15,16}$ Both showed a $27 \%-30 \%$ pain reduction (moderate) in the Short Form-McGill Pain Questionnaire (SF-MPQ) with sodium valproate compared to placebo, and QOL was not measured. Both studies were conducted by the same principal investigator at the same center but in separate populations with small numbers of patients; each study was remarkable for the lack of any change in placebo patients and for the lack of side effects typically attributed to sodium valproate. Treatment allocation concealment was not described.

One Class II study evaluated the efficacy of topiramate. ${ }^{17}$ The study reported a small effect compared to placebo, $7 \%$ net pain reduction on the VAS, and an NNT of 6.6 for $>30 \%$ pain reduction.

Three Class II studies evaluated the efficacy of oxcarbazepine. ${ }^{18-20}$ Two studies showed no benefit, ${ }^{18,20}$ but a third showed a moderate benefit $-17 \%$ more patients on oxcarbazepine had a $>50 \%$ pain reduction compared to placebo, with an NNT of 6.023. ${ }^{19}$ The study showing a positive response had a slightly higher completion rate $\left(73 \%{ }^{19}\right.$ compared to 67\%). ${ }^{20}$ Short Form-Quality of Life (SF-QOL) scores were not improved.

Three Class III studies evaluated the efficacy of lacosamide. ${ }^{21-23}$ All the studies showed a small reduction in pain with $400 \mathrm{mg} /$ day of lacosamide (3\%, $6 \%$, and $6 \%$ compared to placebo), but in 2 studies no significant differences compared to placebo were observed with $600 \mathrm{mg} /$ day of lacosamide. ${ }^{22,23}$ In one study, benefits on general activity and sleep interference QOL measures were observed. ${ }^{21}$

Conclusions. Based on consistent Class I evidence, pregabalin is established as effective in lessening the pain of PDN. Pregabalin also improves QOL and lessens sleep interference, though the effect size is small. Based on one Class I study, gabapentin is probably effective in lessening the pain of PDN. Based on 2 Class II studies, sodium valproate is probably effective in treating PDN. Lamotrigine is probably not effective in treating PDN. Based on Class II evidence, oxcarbazepine is probably not effective in treating PDN. There is conflicting Class III evidence for the effectiveness of topiramate in treating PDN. Based on Class III evidence, lacosamide is possibly not effective in treating PDN. The degree of pain relief afforded by anticonvulsant agents is not associated with improved physical function.

Recommendations

1. If clinically appropriate, pregabalin should be offered for the treatment of PDN (Level A).

2. Gabapentin and sodium valproate should be considered for the treatment of PDN (Level B).

3. There is insufficient evidence to support or refute the use of topiramate for the treatment of PDN (Level $U$ )

. Oxcarbazepine, lamotrigine, and lacosamide should probably not be considered for the treatment of PDN (Level B).

Clinical context. Although sodium valproate may be effective in treating PDN, it is potentially teratogenic and should be avoided in diabetic women of childbearing age. Due to potential adverse effects such as weight gain and potential worsening of glycemic control, this drug is unlikely to be the first treatment choice for PDN.

Antidepressants. We identified 14 articles relevant to antidepressants rated higher than Class IV (table e-2). Seventeen articles were excluded. Most of the RCTs rated as Class II instead of Class I had completion rates of less than $80 \%$.

Two studies (1 Class I and 1 Class II) evaluated the efficacy of venlafaxine. ${ }^{24,25}$ The Class I study reported a moderate effect of venlafaxine, with 23\% more pain relief than with placebo on the VAS-PI $(0-100)$ scale and an NNT of $5 .{ }^{24}$ In the Class II study, venlafaxine plus gabapentin showed a moderate effect in relieving pain on the 11-point Likert scale in PDN, with $18 \%$ more relief than with placebo plus gabapentin. ${ }^{25}$ The QOL measures of bodily pain, mental health, and vitality improved on the SF-36.

Three studies (1 Class I and 2 Class II) evaluated the efficacy of duloxetine in PDN. ${ }^{26-28}$ The Class I study showed that duloxetine had a small effect compared to placebo, reducing pain by $8 \%$ on the 11 point Likert scale ${ }^{26}$; QOL was not assessed. In 2 Class II studies, duloxetine reduced pain (measured by VAS) $13 \%$ more than placebo, ${ }^{27,28}$ but in one study, a moderate effect was shown in responder analysis, with $26 \%$ more responders on duloxetine 
$120 \mathrm{mg} /$ day (total 52\%) than placebo (26\%) (responders defined as those patients having $50 \%$ reduction in their 24-hour average pain score). ${ }^{27}$ The completion rate in both studies was about $75 \% .^{27,28}$ Duloxetine reduced interference with general activity and improved SF-36 and EQ-5D ${ }^{\mathrm{TM}}$ scores. ${ }^{27,28}$

Three studies (1 Class I and 2 Class II) evaluated the efficacy of amitriptyline. ${ }^{29-31}$ The Class I study showed a large responder effect with amitriptyline, with $43 \%$ more responders with amitriptyline than with placebo (requiring at least 20\% pain reduction for responder status). A third group in this study that was treated with maprotiline had $18 \%$ more responders than the placebo group. ${ }^{29}$ In 2 Class II studies, amitriptyline had a large effect, reducing pain by $63 \%$ and $58 \%$ more than placebo on a verbal 13 item descriptor list converted to a numeric 5-point scale. ${ }^{30,31}$ In one of these Class II studies, an active placebo was used. ${ }^{30}$

Two Class III trials evaluated other tricyclic antidepressants (imipramine and nortriptyline). ${ }^{32,33}$ One Class III study showed that $47 \%$ more subjects on imipramine improved on a global evaluation compared to the placebo group, but there was no difference on a 6-point symptom scale. ${ }^{32}$ Another Class III study showed a large effect with the combination of nortriptyline plus fluphenazine compared to placebo; $63 \%$ more patients had a $50 \%$ or greater VAS reduction in the combination group. ${ }^{33}$ One Class III study compared desipramine, amitriptyline, fluoxetine, and placebo and found a small effect ( $6 \%$ pain reduction) for both amitriptyline and desipramine but not for fluoxetine on a 13-word scale converted to 5 points. ${ }^{34}$

Conclusions. Based on 3 Class I and 5 Class II studies, the antidepressants amitriptyline, venlafaxine, and duloxetine are probably effective in lessening the pain of PDN. Venlafaxine and duloxetine also improve QOL. Venlafaxine is superior to placebo in relieving pain when added to gabapentin. There is insufficient evidence to determine whether desipramine, imipramine, fluoxetine, or the combination of nortriptyline and fluphenazine are effective for the treatment of PDN.

Recommendation

1. Amitriptyline, venlafaxine, and duloxetine should be considered for the treatment of PDN (Level B). Data are insufficient to recommend one of these agents over the others.

2. Venlafaxine may be added to gabapentin for a better response (Level C).

3. There is insufficient evidence to support or refute the use of desipramine, imipramine, fluoxetine, or the combination of nortriptyline and fluphenazine in the treatment of PDN (Level U).
Opioids. We identified 9 articles relevant to opioids graded higher than Class IV (table e-3). Most of the RCTs rated as Class II instead of Class I had completion rates of less than $80 \%$.

One Class I study showed that dextromethorphan relieved pain moderately by $16 \%$ more than placebo on a 20-point Gracely Box scale in PDN and improved SF-36 results. ${ }^{35}$ In one Class II study, dextromethorphan with benztropine reduced pain by $24 \%$ more than placebo on a 6 -point scale, a moderate reduction. ${ }^{36}$

A Class II study showed that morphine sulfate had a small effect and reduced pain from baseline by $15 \%$ on the SF-MPQ and improved SF-36 and Beck Depression Inventory results. ${ }^{37}$

In 2 Class $\mathrm{II}$ studies, tramadol relieved pain moderately (16\% and $20 \%$ more than placebo on a Likert scale) in $\mathrm{PDN}^{38,39}$ and improved physical function. ${ }^{38}$

In 3 Class II studies, oxycodone controlled-release and Ultracet (tramadol + acetaminophen) relieved pain in PDN. ${ }^{40, \mathrm{e} 1, \mathrm{e} 2}$ Oxycodone had a small effect, with $9 \%$ more pain relief on the Pain Inventory than placebo. It also improved sleep quality by $7 \%$ more than placebo, but did not change SF-36 scores. ${ }^{40} \mathrm{Ul}-$ tracet improved pain relief by $13 \%$ on the VAS, a small effect, and also improved SF-36 scores by $10 \% .{ }^{\text {e1 }}$ Oxycodone controlled-release had a moderate effect on pain $(27 \%$ reduction in the VAS compared to placebo), improved disability by $10 \%$, and improved most SF-36 subscores. ${ }^{\text {e2 }}$

Conclusions. Based on one Class I study, dextromethorphan is probably effective in lessening the pain of PDN and improving QOL. Based on Class II evidence, morphine sulfate, tramadol, and oxycodone controlledrelease are probably effective in lessening the pain of PDN. Dextromethorphan, tramadol, and oxycodone controlled-release have moderate effect sizes, reducing pain by $27 \%$ compared with placebo.

Recommendations. Dextromethorphan, morphine sulfate, tramadol, and oxycodone should be considered for the treatment of PDN (Level B). Data are insufficient to recommend one agent over the other.

Clinical context. The use of opioids for chronic nonmalignant pain has gained credence over the last decade due to the studies reviewed in this article. Both tramadol and dextromethorphan were associated with substantial adverse events (e.g., sedation in 18\% on tramadol and $58 \%$ on dextromethorphan, nausea in $23 \%$ on tramadol, and constipation in $21 \%$ on tramadol). The use of opioids can be associated with the development of novel pain syndromes such as rebound headache. Chronic use of opioids leads to tolerance and frequent escalation of dose. 
Other pharmacologic agents. We identified 18 articles relevant to other pharmacologic agents rated higher than Class IV (table e-4). Thirteen other articles were excluded. Most of the RCTs rated Class II instead of Class I had completion rates of less than $80 \%$, and those rated Class III often lacked predefined endpoints.

One Class I study of $0.075 \%$ capsaicin showed a large effect, with $40 \%$ more pain reduction on the VAS compared to vehicle cream. ${ }^{\text {e3 }}$ One Class II study showed that $0.075 \%$ capsaicin reduced pain in PDN with a small effect size of $13 \%$ in VAS compared to vehicle cream. ${ }^{\mathrm{e}}$

One Class I study of isosorbide dinitrate spray showed a moderate effect, with $18 \%$ more pain reduction on the VAS relative to placebo. ${ }^{\mathrm{e} 5}$

One Class I study of clonidine and pentoxifylline compared to placebo did not show an effect of these drugs on PDN. ${ }^{\text {e6 }}$

One Class I study of mexiletine did not show an effect on PDN. ${ }^{\text {e7 }}$ Two Class II studies both showed pain reduction with mexiletine, one with a large effect $(37 \% \text { more pain reduction than placebo })^{\mathrm{e} 8}$ and one with a small effect (5\% difference compared to placebo). ${ }^{\text {e9 }}$ Sleep disturbance was reduced in the first Class II study ${ }^{\mathrm{e} 8}$ but not in the second. ${ }^{\mathrm{e}}$

In a single Class I study of sorbinil, pain relief was not observed. ${ }^{\text {e10 }}$

One Class I and 2 Class II studies showed benefit from $\alpha$-lipoic acid in reducing pain in PDN, but pain was not a predefined endpoint in these studies. $^{\text {e11-e13 }}$ The effect size in pain reduction was moderate (20\%-24\% superior to placebo).

In 2 Class III studies, IV lidocaine decreased pain relative to placebo infusion. ${ }^{\mathrm{e} 14, \mathrm{e} 15}$ In one study, a transient decrease of $75 \%$ was observed in a 5-point symptom scale, compared to a decrease of $50 \%$ with placebo infusion. ${ }^{\text {e14 }}$ In the other study, the McGill Pain Questionnaire improved by a small amount (9\% reduction in present pain intensity) with lignocaine, and the differences with placebo were significant due to worsening in the placebo group. ${ }^{\mathrm{e} 15}$ The baseline values were not provided.

In 2 Class III studies, the Lidoderm patch improved pain scores with a moderate to large effect (20\%-30\% reduction in pain scores from baseline and $70 \%$ of patients experienced more than a $30 \%$ decrease in pain). ${ }^{\text {e16,e17 }}$

Conclusions. Based on Class I and Class II evidence, capsaicin cream is probably effective in lessening the pain of PDN. Based on Class III studies, there is insufficient evidence to determine if IV lidocaine is effective in lessening the pain of PDN. Based on Class III evidence, the Lidoderm patch is possibly effective in lessening the pain of PDN. Based on
Class I evidence, clonidine and pentoxifylline are probably not effective for the treatment of PDN. The evidence for the effectiveness of mexiletine is contradictory; however, the only Class I study of this agent indicates that mexiletine is probably ineffective for the treatment of PDN. There is insufficient evidence to determine whether vitamins and $\alpha$-lipoic acid are effective for the treatment of PDN. Based on Class I evidence, isosorbide dinitrate spray is probably effective for the treatment of PDN.

Recommendations

1. Capsaicin and isosorbide dinitrate spray should be considered for the treatment of PDN (Level B).

2. Clonidine, pentoxifylline, and mexiletine should probably not be considered for the treatment of PDN (Level B).

3. The Lidoderm patch may be considered for the treatment of PDN (Level C).

There is insufficient evidence to support or refute the usefulness of vitamins and $\alpha$-lipoic acid in the treatment of PDN (Level U).

Clinical context. Although capsaicin has been effective in reducing pain in PDN clinical trials, many patients are intolerant of the side effects, mainly burning pain on contact with warm/hot water or in hot weather.

In patients with PDN, what is the efficacy of nonpharmacologic modalities to reduce pain and improve physical function and QOL? We identified 11 articles relevant to nonpharmacologic treatment of PDN graded higher than Class IV (table e-5). Only articles on electrical stimulation, Reiki therapy, lowintensity laser therapy, and magnetized shoe insoles reached evidence levels sufficient for discussion in the text. Surgical decompression was addressed in a previous AAN practice advisory ${ }^{\mathrm{e} 18}$ and will not be considered further in this article.

Electrical stimulation. One Class I study reported that percutaneous electrical nerve stimulation reduced pain in PDN by a large magnitude ( $42 \%$ on the VAS) compared with the reduction observed with sham treatment, and also improved sleep. ${ }^{\text {e19 }}$ One Class II study reported no effect with electrical stimulation, ${ }^{\text {e20 }}$ and one Class II study of frequencymodulated electromagnetic neural stimulation showed a small degree of pain relief $(11 \%$ on the VAS) in a crossover design, but with no improvement in the placebo group. ${ }^{\text {e21 }}$

One Class III study showed the addition of electrotherapy to amitriptyline was more effective than amitriptyline alone. ${ }^{\text {e22 }}$

Magnetic field treatment. One Class I study using pulsed electromagnetic fields compared with a sham 
device failed to demonstrate an effect in patients with PDN. ${ }^{\text {23 }}$

One Class II study of the use of magnetized shoe insoles in patients with PDN showed a small effect (14\% VAS decrease) at 4 months compared with that from nonmagnetized insoles, but the endpoint of burning pain was not predetermined. ${ }^{24}$

Other interventions. One Class I study on the use of low-intensity laser treatment compared to sham treatment did not show an effect on pain. ${ }^{\text {e25 }}$

Reiki therapy is defined as the transfer of energy from the practitioner to the patient to enable the body to heal itself through balancing energy. One Class I study of Reiki therapy did not show any effect on PDN. ${ }^{\text {e26 }}$

Other interventions such as exercise and acupuncture do not have any evidence for efficacy in treating PDN.

Conclusion. Based on a Class I study, electrical stimulation is probably effective in lessening the pain of PDN and improving QOL. Based on single Class I studies, electromagnetic field treatment, lowintensity laser treatment, and Reiki therapy are probably not effective for the treatment of PDN. There is not enough evidence to support or exclude a benefit of amitriptyline plus electrotherapy in treating PDN.

Recommendations

1. Percutaneous electrical nerve stimulation should be considered for the treatment of PDN (Level B).

2. Electromagnetic field treatment, low-intensity laser treatment, and Reiki therapy should probably not be considered for the treatment of PDN (Leyel B).

3. Evidence is insufficient to support or refute the use of amitriptyline plus electrotherapy for treatment of PDN (Level $U$ ).

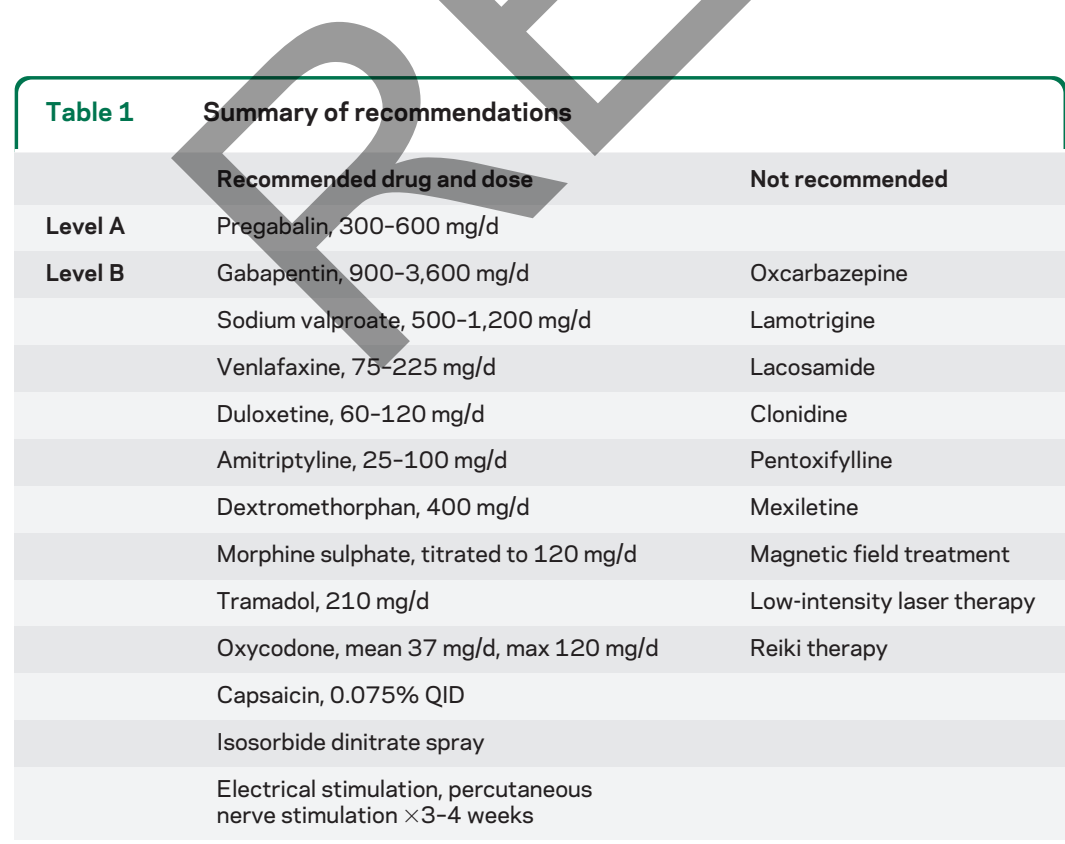

Comparison studies. Studies with 2 active treatment arms and without a placebo arm were considered separately and graded using active control equivalence criteria (appendix e-2; table e-6). We identified 6 comparison studies of agents but did not find sufficient evidence to recommend one over the other. ${ }^{\text {e27-e32 }}$ The comparisons were gabapentin to amitriptyline, ${ }^{2}$ venlafaxine to carbamazepine, nortriptyline + fluphenazine to carbamazepine, capsaicin to amitriptyline, and benfothiamine + cyanocobalamin with conventional vitamin B. None of the studies defined the threshold for equivalence or noninferiority.

CLINICAL CONTEXT SUMMARY FOR ALL EVIDENCE It is notable that the placebo effect varied from $0 \%$ to $50 \%$ pain reduction in these studies.

Adjuvant analgesic agents are drugs primarily developed for an indication other than treatment of PDN (e.g., anticonvulsants and antidepressants) that have been found to lessen pain when given to patients with PDN. Their use in the treatment of PDN is common. ${ }^{\text {33 }}$ The panel recognizes that PDN is a chronic disease and that there are no data on the efficacy of the chronic use of any treatment, as most trials have durations of 2-20 weeks. It is important to note that the evidence is limited, the degree of effectiveness can be minor, the side effects can be intolerable, the impact on improving physical function is limited, and the cost is high, particularly for novel agents.

A summary of Level A and B recommendations for the treatment of PDN is provided in table 1 .

\section{RECOMMENDATIONS FOR FUTURE RESEARCH}

1. A formalized process for rating pain scales for use in all clinical trials should be developed.

2. Clinical trials should be expanded to include effects on QOL and physical function when evaluating efficacy of new interventions for PDN; the measures should be standardized.

3. Future clinical trials should include head-to-head comparisons of different medications and combinations of medications.

4. Because PDN is a chronic disease, trials of longer duration should be done.

5. Standard metrics for side effects to qualify effect sizes of interventions need to be developed.

6. Cost-effectiveness studies of different treatments should be done.

7. The mechanism of action of electrical stimulation is unknown; a better understanding of its role, mode of application, and other aspects of its use should be studied.

\section{DISCLOSURE}

Dr. Bril has received research support from Talecris Biotherapeutics, Eisai Inc., Pfizer Inc, Eli Lilly and Company, and Johnson \& Johnson. Dr. England serves on the speakers' bureau for and has received funding for 
travel or speaker honoraria from Talecris Biotherapeutics and Teva Pharmaceutical Industries Ltd.; served as an Associate Editor for Current Treatment Options in Neurology; receives research support from the NIH/ NINDS, Wyeth, Astra Zeneca, and Pfizer Inc; holds stock/stock options in Wyeth and Talecris Biotherapeutics; and has served as an expert witness in a medico-legal case. Dr. Franklin serves on the editorial board of Neuroepidemiology; serves as a consultant for the New Zealand Accident Fund; and serves as a consultant for the Workers Compensation Research Institute. Dr. Backonja served on a Safety Monitoring Board for Medtronic, Inc.; serves on the editorial boards of Clinical Journal of Pain, European Journal of Pain, Journal of Pain, Pain, and Pain Medicine; is listed as author on a patent re: A hand-held probe for suprathreshold thermal testing in patients with neuropathic pain and other neurological sensory disorders; serves as a consultant for Allergan, Inc., Astellas Pharma Inc., Eli Lilly and Company, Medtronic, Inc., Merck Serono, NeurogesX, Pfizer Inc, and SK Laboratories, Inc.; and receives research support from NeurogesX. Dr. Cohen serves on an FDA Peripheral and Central Nervous System Drugs Advisory Committee; receives publishing royalties for What Would You Do Now? Neuromuscular Disease (Oxford University Press, 2009); estimates that he performs clinical neurophysiology testing as 50\% of his clinical practice; and has given expert testimony, prepared an affidavit, and acted as a witness in a legal proceeding with regard to vaccinerelated injuries and peripheral nerve injuries. Dr. Del Toro receives research support from the NIH. Dr. Feldman serves on a Data Safety and Monitoring Board for Novartis; serves on the editorial boards of Annals of Neurology and the Journal of the Peripheral Nervous System; receives publishing royalties from UpToDate; and receives research support from the $\mathrm{NIH}$, the Taubman Research Institute, and the American Diabetes Association. Dr. Iverson serves as editor of NeuroPI and has been a treating expert witness with regard to a legal proceeding. Dr. Perkins has received research support from Medtronic, Inc., the Canadian Institutes of Health Research, the Juvenile Diabetes Research Foundation, and the Canadian Diabetes Association. Dr. Russell has received honoraria from Exelixis Inc. and Baxter International Inc.; and receives research support from Baxter International Inc., the NIH, the US Veterans Administration, the American Diabetes Association, and the Juvenile Diabetes Foundation. Dr. Zochodne serves on a scientific advisory board for and holds stock options in Aegera Therapeutics Inc.; has received honoraria from Ono Pharmaceutical Co. Ltd.; receives publishing royalties for Neurobiology of Peripheral Nerve Regeneration (Cambridge University Press, 2008); has received research support from the Canadian Institutes of Health Research, the Canadian Diabetes Association, the Juvenile Diabetes Research Foundation, the National Science and Engineering Research Council, the NIH, and the Alberta Heritage Foundation for Medical Research, Baxter International Inc., and Aegera Therapeutics Inc.; and has served as a co-PI on industry trials with Valeant Pharmaceuticals International and Pfizer Inc.

\section{DISCLAIMER}

This statement is provided as an educational service of the American Academy of Neurology. It is based on an assessment of current scientific and clinical information. It is not intended to include all possible proper methods of care for a particular neurologic problem or all legitimate criteria for choosing to use a specific procedure. Neither is it intended to exclude any reasonable alternative methodologies. The AAN recognizes that specific patient care decisions are the prerogative of the patient and the physician caring for the patient, based on all of the circumstances involved. The clinical context section is made available in order to place the evidence-based guideline(s) into perspective with current practice habits and challenges. No formal practice recommendations should be inferred.

\section{CONFLICT OF INTEREST}

The American Academy of Neurology is committed to producing independent, critical and truthful clinical practice guidelines (CPGs). Significant efforts are made to minimize the potential for conflicts of interest to influence the recommendations of this CPG. To the extent possible, the AAN keeps separate those who have a financial stake in the success or failure of the products appraised in the CPGs and the developers of the guidelines. Conflict of interest forms were obtained from all authors and reviewed by an oversight committee prior to project initiation. AAN lim- its the participation of authors with substantial conflicts of interest. The AAN forbids commercial participation in, or funding of, guideline projects. Drafts of the guidelines have been reviewed by at least three AAN committees, a network of neurologists, Neurology ${ }^{\circledR}$ peer reviewers, and representatives from related fields. The AAN Guideline Author Conflict of Interest Policy can be viewed at www.aan.com.

Received December 15, 2010. Accepted in final form February 15, 2011.

\section{REFERENCES}

1. Boulton AJ, Vinik AI, Arezzo JC, et al. Diabetic neuropathies: a statement by the American Diabetes Association. Diabetes Care 2005;28:956-962.

2. Gordois A, Scuffham P, Shearer A, Oglesby A, Tobian JA. The health care costs of diabetic peripheral neuropathy in the US. Diabetes Care 2003;26:1790-1795.

3. Daousi C, MacFarlane IA, Woodward A, Nurmikko TJ, Bundred PE, Benbow SJ. Chronic painful peripheral neuropathy in an urban community: a controlled comparison of people with and without diabetes. Diabet Med 2004;21: 976-982.

Farrar JT, Berlin JA, Strom BL. Clinically important changes in acute pain outcome measures: a validation study. J Pain Symptom Manage 2003;25:406-411.

Farrar JT, Pritchett YL, Robinson M, Prakash A, Chappell A. The clinical importance of changes in the 0 to $10 \mathrm{nu}-$ meric rating scale for worst, least, and average pain intensity: analyses of data from clinical trials of duloxetine in pain disorders. J Pain 2010;11:109-118.

6. Farrar JT, Young JP Jr, LaMoreaux L, Werth JL, Poole RM. Clinical importance of changes in chronic pain intensity measured on an 11-point numerical pain rating scale. Pain 2001;94:149-158.

7. Lesser H, Sharma U, LaMoreaux L, Poole RM. Pregabalin relieves symptoms of painful diabetic neuropathy: a randomized controlled trial. Neurology 2004;63:2104-2110.

8. Richter RW, Portenoy R, Sharma U, Lamoreaux L, Bockbrader H, Knapp LE. Relief of painful diabetic peripheral neuropathy with pregabalin: a randomized, placebocontrolled trial. J Pain 2005;6:253-260.

9. Rosenstock J, Tuchman M, LaMoreaux L, Sharma U. Pregabalin for the treatment of painful diabetic peripheral neuropathy: a double-blind, placebo-controlled trial. Pain 2004; 110:628-638.

10. Freynhagen R, Strojek K, Griesing T, Whalen E, Balkenohl M. Efficacy of pregabalin in neuropathic pain evaluated in a 12-week, randomised, double-blind, multicentre, placebo-controlled trial of flexible- and fixed-dose regimens. Pain 2005;115:254-263.

11. Backonja M, Beydoun A, Edwards KR, et al. Gabapentin for the symptomatic treatment of painful neuropathy in patients with diabetes mellitus: a randomized controlled trial. JAMA 1998;280:1831-1836.

12. Gorson KC, Schott C, Herman R, Ropper AH, Rand WM. Gabapentin in the treatment of painful diabetic neuropathy: a placebo controlled, double blind, crossover trial. J Neurol Neurosurg Psychiatry 1999;66:251-252.

13. Eisenberg E, Lurie Y, Braker C, Daoud D, Ishay A. Lamotrigine reduces painful diabetic neuropathy: a randomized, controlled study. Neurology 2001;57:505-509.

14. Vinik AI, Tuchman M, Safirstein B, et al. Lamotrigine for treatment of pain associated with diabetic neuropathy: results of two randomized, double-blind, placebo-controlled studies. Pain 2007;128:169-179. 
15. Kochar DK, Jain N, Agarwal RP, Srivastava T, Agarwal P, Gupta S. Sodium valproate in the management of painful neuropathy in type 2 diabetes: a randomized placebo controlled study. Acta Neurol Scand 2002;106:248-252.

16. Kochar DK, Rawat N, Agrawal RP, et al. Sodium valproate for painful diabetic neuropathy: a randomized double-blind placebo-controlled study. QJM 2004;97: 33-38.

17. Raskin P, Donofrio PD, Rosenthal NR, et al. Topiramate vs placebo in painful diabetic neuropathy: analgesic and metabolic effects. Neurology 2004;63:865-873.

18. Grosskopf J, Mazzola J, Wan Y, Hopwood M. A randomized, placebo-controlled study of oxcarbazepine in painful diabetic neuropathy. Acta Neurol Scand 2006;114:177-180.

19. Dogra S, Beydoun S, Mazzola J, Hopwood M, Wan Y. Oxcarbazepine in painful diabetic neuropathy: a randomized, placebo-controlled study. Eur J Pain 2005;9:543554.

20. Beydoun A, Shaibani A, Hopwood M, Wan Y. Oxcarbazepine in painful diabetic neuropathy: results of a doseranging study. Acta Neurol Scand 2006;113:395-404.

21. Rauck RL, Shaibani A, Biton V, Simpson J, Koch B. Lacosamide in painful diabetic peripheral neuropathy: a phase 2 double-blind placebo-controlled study. Clin J Pain 2007; 23:150-158.

22. Wymer JP, Simpson J, Sen D, Bongardt S. Efficacy and safety of lacosamide in diabetic neuropathic pain: an 18week double-blind placebo-controlled trial of fixed-dose regimens. Clin J Pain 2009;25:376-385.

23. Shaibani A, Biton V, Rauck R, Koch B, Simpson J. Longterm oral lacosamide in painful diabetic neuropathy: a two-year open-label extension trial. Eur J Pain 2009;13: 458-463.

24. Rowbotham MC, Goli V, Kunz NR, Lei D. Venlafaxine extended release in the treatment of painful diabetic neuropathy: a double-blind, placebo-controlled study. Pain 2004;110:697-706.

25. Simpson DA. Gabapentin and venlafaxine for the treatment of painful diabetic neuropathy. J Clin Neuromuscul Dis 2001;3:53-62.

26. Raskin J, Pritchett YL, Wang F, et al. A double-blind, randomized multicenter trial comparing duloxetine with placebo in the management of diabetic peripheral neuropathic pain. Pain Med 2005;6:346-356.

Goldstein DJ, Lu Y, Detke MJ, Lee TC, Iyengar S. Duloxetine vs. placebo in patients with painful diabetic neuropathy. Pain 2005;116:109-118.
28. Wernicke JF, Pritchett YL, D'Souza DN, et al. A randomized controlled trial of duloxetine in diabetic peripheral neuropathic pain. Neurology 2006;67:1411-1420.

29. Vrethem M, Boivie J, Arnqvist H, Holmgren H, Lindstrom T, Thorell LH. A comparison of amitriptyline and maprotiline in the treatment of painful diabetic neuropathy in diabetics and nondiabetics. Clin J Pain 1997;13:313-323.

30. Max MB. Endogenous monoamine analgesic systems: amitriptyline in painful diabetic neuropathy. Anesth Prog 1987;34:123-127.

31. Max MB, Culnane M, Schafer SC, et al. Amitriptyline relieves diabetic neuropathy pain in patients with normal or depressed mood. Neurology 1987;37:589-596.

32. Kvinesdal B, Molin J, Froland A, Gram LF. Imipramine treatment of painful diabetic neuropathy. JAMA 1984; 251:1727-1730.

33. Gomez-Perez FJ, Rull JA, Dies H, Rodriquez-Rivera JG, Gonzalez-Barranco J, Lozano-Castaneda O. Nortriptyline and fluphenazine in the symptomatic treatment of diabetic neuropathy: a double-blind cross-over study. Pain 1985; 23:395-400.

Max MB, Lynch SA, Muir J, Shoaf SE, Smoller B, Dubner R. Effects of desipramine, amitriptyline, and fluoxetine on pain in diabetic neuropathy. N Engl J Med 1992;326: $1250-1256$.

35. Sang CN, Booher S, Gilron I, Parada S, Max MB. Dextromethorphan and memantine in painful diabetic neuropathy and postherpetic neuralgia: efficacy and dose-response trials. Anesthesiology 2002;96:1053-1061.

36. Nelson KA, Park KM, Robinovitz E, Tsigos C, Max MB. High-dose oral dextromethorphan versus placebo in painful diabetic neuropathy and postherpetic neuralgia. Neurology 1997;48:1212-1218.

37. Gilron I, Bailey JM, Tu D, Holden RR, Weaver DF, Houlden RL. Morphine, gabapentin, or their combination for neuropathic pain. N Engl J Med 2005;352:13241334.

38. Harati $Y$, Gooch C, Swenson M, et al. Double-blind randomized trial of tramadol for the treatment of the pain of diabetic neuropathy. Neurology 1998;50:1842-1846.

39. Sindrup SH, Andersen G, Madsen C, Smith T, Brosen K, Jensen TS. Tramadol relieves pain and allodynia in polyneuropathy: a randomised, double-blind, controlled trial. Pain 1999;83:85-90.

40. Gimbel JS, Richards P, Portenoy RK. Controlled-release oxycodone for pain in diabetic neuropathy: a randomized controlled trial. Neurology 2003;60:927-934. 


\section{Neurology}

Evidence-based guideline: Treatment of painful diabetic neuropathy [RETIRED]:

Report of the American Academy of Neurology, the American Association of Neuromuscular and Electrodiagnostic Medicine, and the American Academy of Physical Medicine and Rehabilitation

V. Bril, J. England, G.M. Franklin, et al.

Neurology 2011;76;1758-1765 Published Online before print April 11, 2011

DOI 10.1212/WNL.0b013e3182166ebe

This information is current as of April 11, 2011

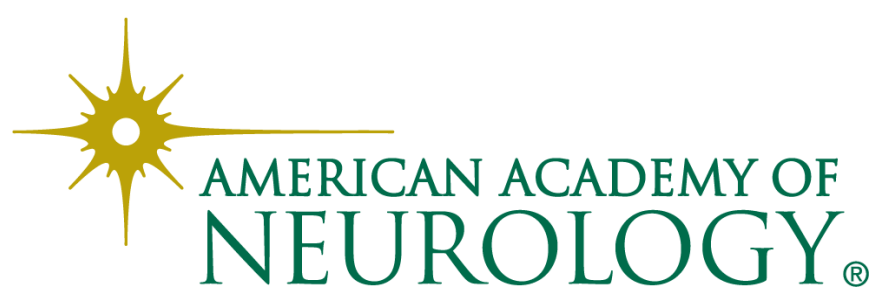




\section{Updated Information \& Services}

\section{Supplementary Material}

Citations

Subspecialty Collections

\section{Errata}

Permissions \& Licensing

Reprints including high resolution figures, can be found at: http://n.neurology.org/content/76/20/1758.full

Supplementary material can be found at: http://n.neurology.org/content/suppl/2011/04/08/WNL.0b013e3182166 ebe.DC1

http://n.neurology.org/content/suppl/2011/10/02/WNL.0b013e3182166 ebe.DC2

http://n.neurology.org/content/suppl/2011/12/20/WNL.0b013e3182166 ebe.DC3

http://n.neurology.org/content/suppl/2012/01/30/WNL.0b013e3182166 ebe.DC4

This article has been cited by 12 HighWire-hosted articles: http://n.neurology.org/content/76/20/1758.full\#\#otherarticles

This article, along with others on similar topics, appears in the following collection(s):

Neuropathic pain

http://n.neurology.org/cgi/collection/neuropathic_pain

Peripheral neuropathy

http://n.neurology.org/cgi/collection/peripheral_neuropathy

An erratum has been published regarding this article. Please see next page or:

/content/77/6/603.full.pdf

Information about reproducing this article in parts (figures,tables) or in its entirety can be found online at:

http://www.neurology.org/about/about_the_journal\#permissions

Information about ordering reprints can be found online:

http://n.neurology.org/subscribers/advertise

Neurology ${ }^{\circledR}$ is the official journal of the American Academy of Neurology. Published continuously since 1951, it is now a weekly with 48 issues per year. Copyright Copyright (? 2011 by AAN Enterprises, Inc.. All rights reserved. Print ISSN: 0028-3878. Online ISSN: 1526-632X.

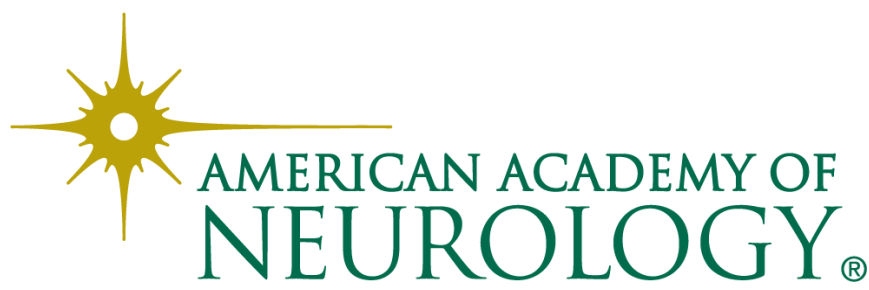


our recent article, ${ }^{1}$ several other groups have reported evidence for MS susceptibility haplotypes tagged by HLA $A^{*} 02$ and HLA B*44 that are independent of the effect of HLA DRB1*1501. The analysis of extended haplotypes published by Chao and colleagues does not find the protective effect of HLA B*44, but its size is too modest to definitively reject the possibility that HLA B*44 (or HLA A*02) tagged haplotypes have a role in MS susceptibility. Thus, clearly, we agree that additional studies with many thousands of subjects with MS and high-resolution sequence data will be needed to definitively deconstruct the role of the MHC in MS susceptibility in terms of HLA A*02, HLA B*44, and the HLA DRB1 alleles that have not yet been consistently replicated across populations and studies.

Comparisons of our results with those of Chao and colleagues is also hampered by methodologic differences. Assessing MHC class I/HLA DRB1 haplotypes is a reasonable approach, but we felt that an assessment of single alleles was more appropriate. As noted in our article, HLA A*02 and HLA B*44 were the most associated alleles after HLA DRB1*1501; other DRB1 alleles had more modest evidence of association than these 2 class I alleles and may be secondary to class I associations. Thus, we did not feel it was appropriate to correct for other HLA DRB1 alleles. Cryptic population structure in our subjects self-reported to be of non-Hispanic European ancestry could affect the distribution of alleles, but even gross imbalance would not explain the full effect of our $2 \mathrm{MHC}$ class I alleles. Uncorrected genome-wide association studies in North American populations of European ancestry can have genomic inflation factors of 1.2 or 1.3 prior to the removal of subjects who are population outliers, but even a very large genomic inflation factor of 2.0 would yield a significant corrected $p$ value of 0.014 for HLA B*44 in our analysis. So, population stratification alone does not explain our result, although we cannot exclude the possibility that it may have contributed to our result since we do not have mathematical estimates of ancestry for our subjects. Family-based analyses such as the transmission disequilibrium test used by Chao and colleagues ${ }^{4}$ have the advantage of obviating concerns about population stratification, but even the very large and useful family-based collection that they explored remains modest in size, limiting its statistical power when compared to existing case-control MS collections in the evaluation of common variants of modest effect.

Overall, we cannot say that HLA $A^{*} 02$ and HLA $\mathrm{B}^{*} 44$ are causal alleles at this time; as noted in our article, they simply represent the best markers of 2 separate HLA DRB1*1501-independent effects within the MHC. We look forward to more studies from the MS genetics community to refine the exact variant or groups of variants that affect MS susceptibility outside of the association tagged by HLA DRB1*1501.

\section{Philip L. De Jager, Boston, $M A$}

Disclosure: See original article for full disclosure list.

Copyright (C) 2011 by AAN Enterprises, Inc.

1. Healy BC, Liguori M, Tran D, et al. HLA B*44: protective effects in MS susceptibility and MRI outcome measures. Neurology 2010;75:634-640.

2. Rioux JD, Goyette P, Vyse TJ, et al. Mapping of multiple susceptibility variants within the MHC region for 7 immune-mediated diseases. Proc Natl Acad Sci USA 2009; 106:18680-18685.

3. Lincoln MR, Montpetit A, Cader MZ, et al. A predominant role for the HLA class II region in the association of the MHC region with multiple sclerosis. Nat Genet 2005; 37:1108-1112.

4. Chao MJ, Barnardo MC, Lincoln MR, et al. HLA class I alleles tag HLA-DRB1*1501 haplotypes for differential risk in multiple sclerosis susceptibility. Proc Natl Acad Sci USA 2008;105:13069-13074.

5. Ramagopalan SV, Morris AP, Dyment DA, et al. The inheritance of resistance alleles in multiple sclerosis. PLoS Genet 2007;3:1607-1613.

\section{CORRECTION}

Evidence-based guideline: Treatment of painful diabetic neuropathy: Report of the American Academy of Neurology, the American Association of Neuromuscular and Electrodiagnostic Medicine, and the American Academy of Physical Medicine and Rehabilitation

In the article "Evidence-based guideline: Treatment of painful diabetic neuropathy: Report of the American Academy of Neurology, the American Association of Neuromuscular and Electrodiagnostic Medicine, and the American Academy of Physical Medicine and Rehabilitation" by V. Bril et al. (Neurology $\left.{ }^{\circledR} 2011 ; 76: 1758-1765\right)$, there was an error in the article text regarding the dosage for the number needed to treat (NNT) and an error in the citation of references 7-9. "The NNT for a $50 \%$ reduction in pain was 4 at $600 \mathrm{~g} /$ day. ${ }^{7-10 "}$ " should read "The NNT for a $50 \%$ reduction in pain was 4 at 600 $\mathrm{mg} /$ day. ${ }^{10 "}$ The authors regret the errors. 